\title{
Dynamical Seasonal Predictability of the Asian Summer Monsoon
}

\author{
K.R. Sperber
}

This article was submitted to

$24^{\text {th }}$ Annual Climate Diagnostics and Prediction Workshop Tucson, AZ

November 1-5, 1999

December 14, 1999

U.S. Department of Energy

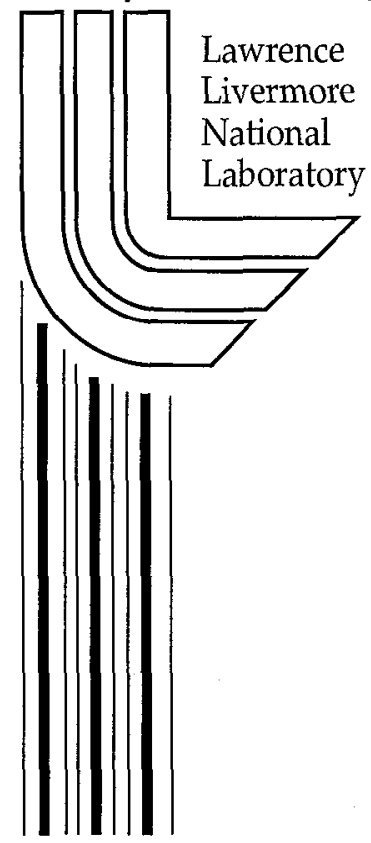




\section{DISCLAIMER}

This document was prepared as an account of work sponsored by an agency of the United States Government. Neither the United States Government nor the Universily of California nor any of their employees, makes any warranty, express or implied, or assumes any legal liability or responsibility for the accuracy, completeness, or usefulness of any information, apparatus, product, or process disclosed, or represents that its use would not infringe privately owned rights. Reference herein to any specific commercial product, process, or service by trade name, trademark, manufacturer, or otherwise, does not necessarily constitute or imply its endorsement, recommendation, or favoring by the United States Government or the University of California. The views and opinions of authors expressed herein do not necessarily state or reflect those of the United States Government or the University of California, and shall not be used for adverlising or product endorsement purposes.

This is a preprinl of a paper intended for publication in a journal or proceedings. Since changes may be made before publication, this preprint is made available with the understanding that it will not be cited or reproduced without the permission of the author.

This report has been reproduced directly from the best available copy.

Available to DOE and DOE contractors from the Office of Scientific and Technical Information

P.O. Box 62, Oak Ridge, TN 37831

Prices available from (423) 576-8401 http://apollo.osti.gov/bridge/

$\Lambda$ vailable to the public from the National Technical Information Service

U.S. Department of Commerce 5285 Port Royal Rd., Springfield, VA 22161 http://www.ntis.gov/

\section{OR}

Lawrence Livermore National Laboratory Technical Information Department's Digital Library http://www.llnl.gov/tid/Library.html 


\title{
Dynamical Seasonal Predictability of the Asian Summer Monsoon
}

\author{
Kenneth R. Sperber ${ }^{1}$ and SMUP Participants \\ (BMRC, CNRM, JMA, and UKMO) \\ ${ }^{1}$ PCMDI, Lawrence Livermore National Laboratory \\ P.O. Box 808, L-264, Livermore, C.A 94550 USA
}

The goals of this paper are to (1) ascertain the ability of atmospheric general circulation models to hindcast the summer monsoons of 1987, 1988, and 1993, (2) to determine how well the models represent the dominant modes of subseasonal variability of the $850 \mathrm{hPa}$ tlow, (3) to determine if the models can represent the strong link between the subseasonal modes of variability and the rainfall, (4) to determine if the models properly project these modes onto interannual timescales, (5) to determine if it is possible to objectively discriminate among the ensemble members to ascertain which members are most reliable.

The results presented here are based upon contributions to the seasonal prediction model intercomparison project (SMIP), which was initiated by the CLIVAR Working Group on Seasonal to Interannual Prediction (WGSIP; formally Numerical Experimentation Group-1). For each summer, June-September, ensembles of integrations were performed using observed initial conditions, and observed sea surface temperatures. Here, the results from a 4-member ensemble from the United Kingdom Met Office (UKMO) model are presented for the sake of brevity. The conclusions based on the analysis of this model are consistent with the behaviour of the other models.

EOF analysis of daily $850 \mathrm{hPa}$ wind is employed to extract the dominant modes of subseasonal variability from the NCEP/NCAR reanalysis and the ensemble members of the UKMO hindcasts (Fig. 1). The observed modes correspond almost exactly to those extracted from 40 years of NCEP/NCAR reanalysis, attesting to the robustness of these modes for controlling variability over the Asian summer monsoon region (Sperber et al. 1999a [Quart. J. Roy. Meteorol. Soc. submitted], 1999b [CLIVAR Exchanges No. 14, December 1999]). EOF-1 (Fig. 1a), associated with the northward propagation of the tropical convergence zone, is especially well simulated by the model (Fig 1b). For EOF-2, the model fails to properly capture the flow over East Asia, and EOF-4 from the model (Fig. 1f) crudely captures the anticyclone/cyclone pattern in the vicinity of India seen clearly in EOF-3 from the NCEP/NCAR Reanalysis (Fig. 1e). Composite differences of rainfall (not shown) based on days when the principal components exceed $+/-1$ standard deviation thresholds confirm that the model modes correspond to the observed modes.

As discussed in Sperber et al. (1999a, 1999b) the seasonal mean of each principal component time series gives the projection of that mode onto the interannual variability. The projections of the ensemble members and validation from NCEP/NCAR reanalysis are given in Table 1 . Those realizations that were able to capture the correct signs of the projections for all three modes during a given year are shaded. In 1987 the model was unable to capture the correct projections of all three modes onto the interannual variability, and as such the model failed to even qualitatively capture the precipitation and $850 \mathrm{hPa}$ wind anomalies (not shown). Rather the model incorrectly produced enhanced rainfall over India in 1987. This is consistent with the systematic error of this model in that it produces enhanced rainfall over India during El Niño conditions (J. M. Slingo, personal communication, 1999). In 1988, 3 of 4 members did not properly simulate the projection onto interannual timescales (Table 1). While the model does qualitatively represent the southeasterly anomalies in the vicinity of the monsoon trough (Fig. $2 \mathrm{c}, 80^{\circ} \mathrm{E}, 20^{\circ} \mathrm{N}$ ) it fails to capture the onshore flow and cyclonic circulation anomalies near the west coast of India, and it overestimates the cyclonic anomalies at the head of the Bay of Bengal seen in the NCEP/NCAR reanalysis (Fig. 2a). Hence the model (Fig. 2d) fails to capture the enhanced rainfall over the whole of the Indian subcontinent, and it overestimates the negative rainfall anomalies over the Bay of Bengal compared to the observed anomalies (Fig. 2b). However, as seen in Table 1, the integration that was run using the 31 May 1988 initial conditions successfully captured the correct sign of the projections of all 3 modes, and as seen in Figs. 2e-f, this member more realistically represents the observed rainfall and $850 \mathrm{hPa}$ wind anomalies. 
In particular, it better represents the orientation of the wind anomalies in the monsoon trough, it has a tendency for onshore flow near southern India, it has cyclonic anomalies near the west coast of India, and the cyclonic anomalies over the Bay of Bengal are not as strong relative to the anomalies calculated using all members (Fig. 2c). Consequently, the 31 May 1998 member more realistically represents the enhance rainfall over India and the reduced rainfall over the Bay of Bengal. During 1993 three of four members give the proper projections of the subseasonal modes onto the interannual variability, and as a consequence the wind and rainfall anomalies are better captured during this summer (not shown). The 29 May 1993 integration was unable to capture the correct projections onto the interannual variability, and its removal from the ensemble yields further improvement in the wind and rainfall anomalies (not shown).

To varying degree the models represent some but not all of the dominant modes of subseasonal variability during the Asian summer monsoon. For the afore-mentioned modes, the models represent the subseasonal link between the $850 \mathrm{hPa}$ flow and the rainfall. However, in most cases the models do not properly represent the projection of these modes onto the interannual variability. Consequently, the hindcasts are typically poor. When an ensemble member qualitatively represents the seasonal projections of the individual modes, then that member gives a more realistic representation of the observed seasonal anomalies of $850 \mathrm{hPa}$ wind and precipitation. The converse is also true. At least 2 possible causes exist for the poor performance of the hindcasts. These include the strong spin-up due to the initial shock of using observed initial conditions (not shown) which are out of balance with the usual parameter space of the model. Additionally, systematic errors of the model climatologies need to be reduced since this is associated with improper simulation of remote teleconnections.

Acknowledgments. Dr. K. R. Sperber was supported under the auspices of the U.S. Department of Energy Environmental Sciences Division at the Lawrence Livermore National Laboratory under Contract W-7405-ENG-48. I wish to thank the modelling groups for contributing their data to this project.

Table 1: Seasonal means (June-September) of the principal components of the daily $850 \mathrm{hPa}$ wind for 1987, 1988 and 1993. Those realizations that were able to capture the correct signs of the projections for all three modes during a given year are shaded.

\begin{tabular}{|c|c|r|r|r|}
\hline Year/1.C. & Source & \multicolumn{1}{|c|}{$\overline{\text { PC-1 }}$} & $\overline{\text { PC-2 }}$ & $\overline{\text { PC-3* }}$ \\
\hline \hline 1987 & NCEP & -2.0 & -5.0 & -6.7 \\
\hline 28 May & UKMO & 19.2 & 6.0 & 1.8 \\
\hline 29 May & UKMO & 31.9 & -5.7 & 14.0 \\
\hline 30 May & UKMO & -8.8 & 12.0 & 2.0 \\
\hline 31 May & UKMO & 23.7 & 7.4 & 2.8 \\
\hline 1988 & NCEP & -6.8 & -8.7 & $\mathbf{1 0 . 6}$ \\
\hline 28 May & UKMO & -26.1 & -12.0 & -2.5 \\
\hline 29 May & UKMO & -32.8 & 0.5 & 0.6 \\
\hline 30 May & UKMO & -27.2 & -13.8 & -5.7 \\
\hline 31 May & UKMO & -18.2 & -4.7 & 8.8 \\
\hline 1993 & NCEP & 8.8 & 13.7 & -3.9 \\
\hline 28 May & UKMO & 17.7 & 14.5 & -5.9 \\
\hline 29 May & UKMO & -11.8 & -9.3 & -2.0 \\
\hline 30 May & UKMO & 8.8 & 3.1 & -6.7 \\
\hline 31 May & UKMO & 23.7 & 1.9 & -7.4 \\
\hline
\end{tabular}

* $\overline{\mathrm{PC}-4}$ from UKMO 
NCEP/NCAR

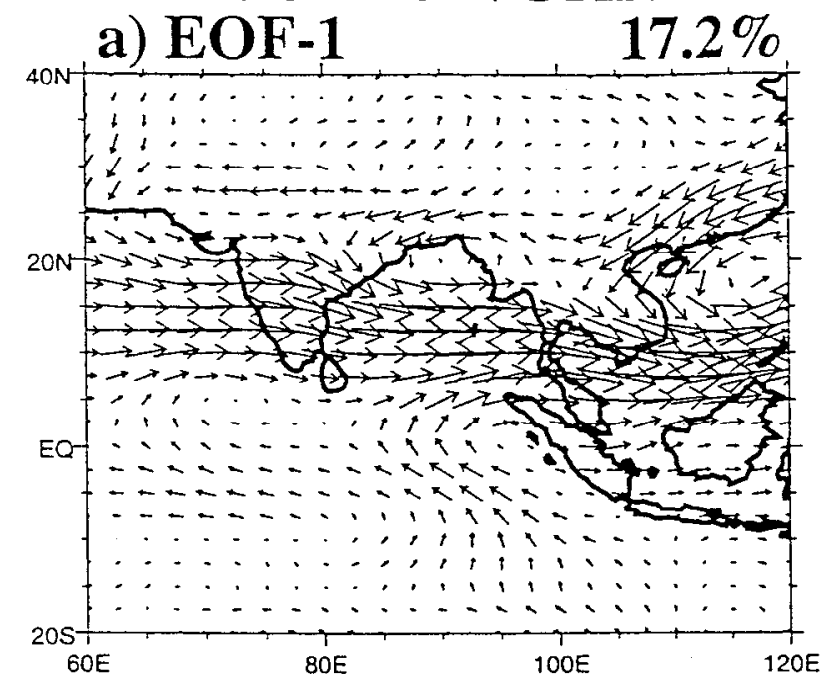

c) EOF-2

$8.3 \%$
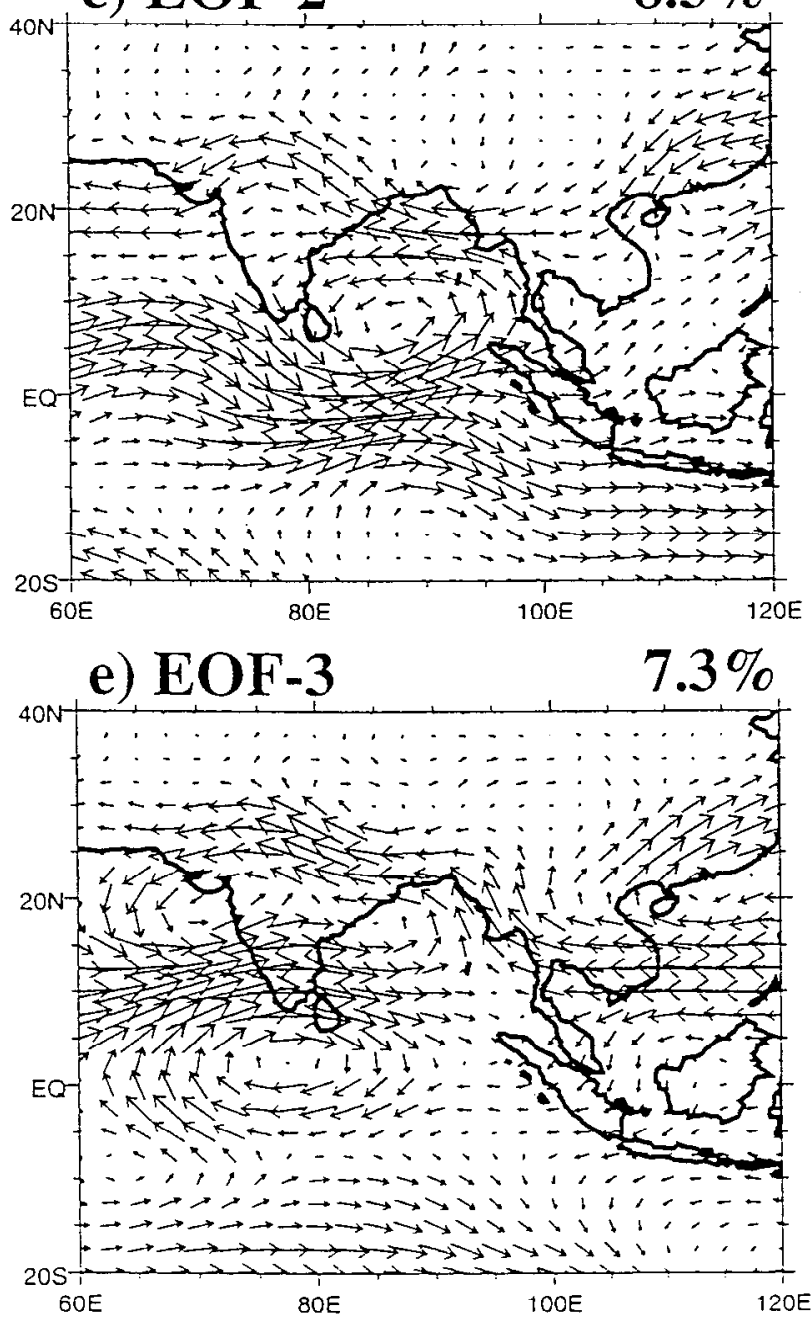

$\overrightarrow{0.1}$
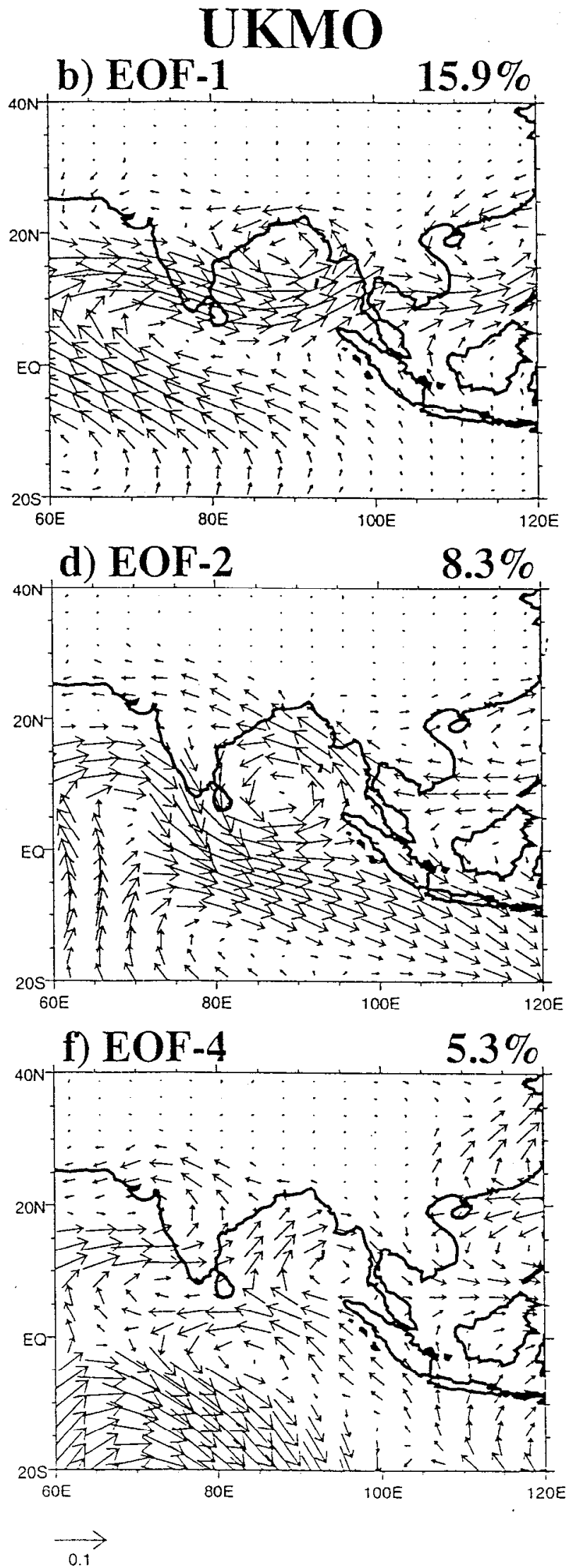

Figure 1: Results of an EOF analysis of daily $850 \mathrm{hPa}$ wind anomalies for June-September 1987 , 1988, and 1993. Prior to the analysis the climatological daily means have been removed. EOF-1: (a) NCEP/NCAR, (b) UKMO; EOF-2: (c) NCEP/NCAR, (d) UKMO; EOF-3: (e) NCEP/NCAR, (f) UKMIO. The percent variance explained by each mode is also given. 
a) NCEP/NCAR

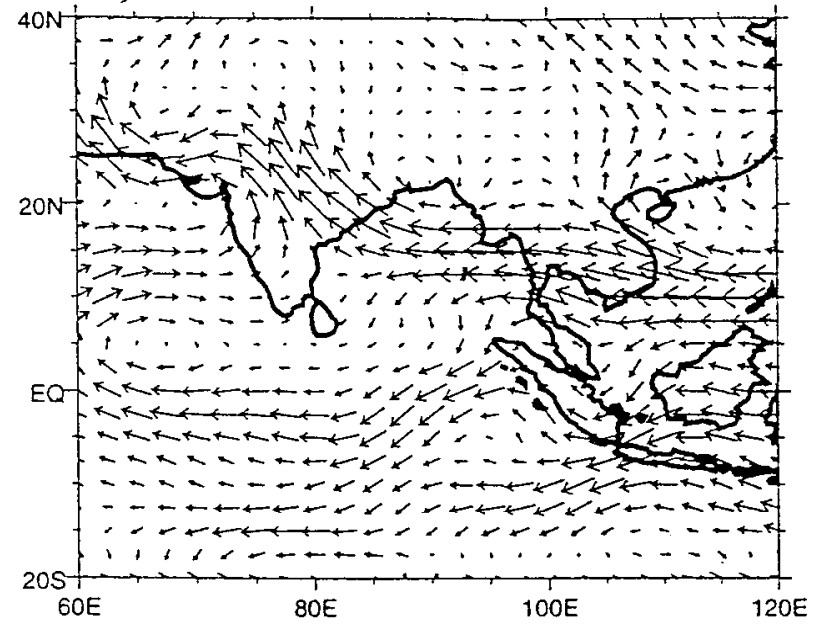

c) UKMO Ensemble mean

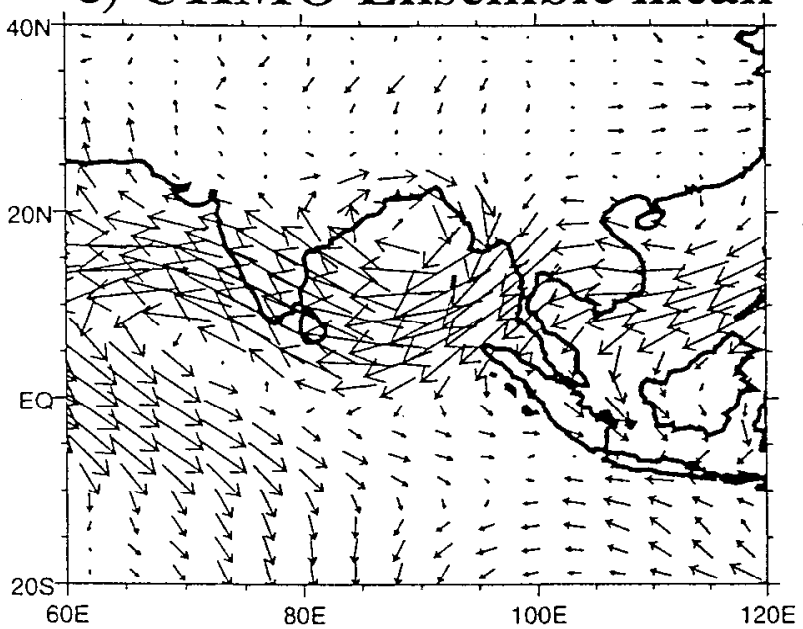

e) UKMO 31 May I.C.

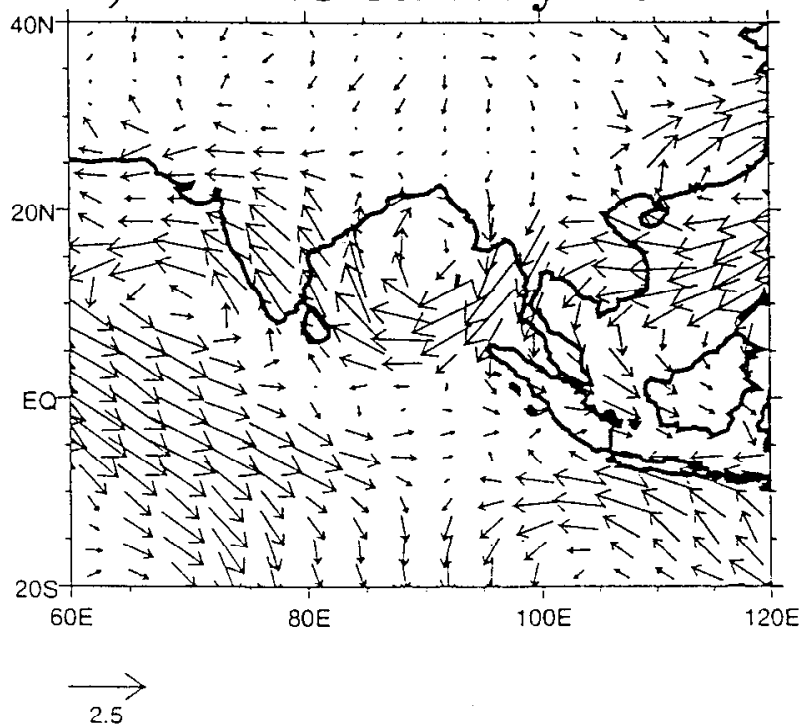

b) Xie-Arkin

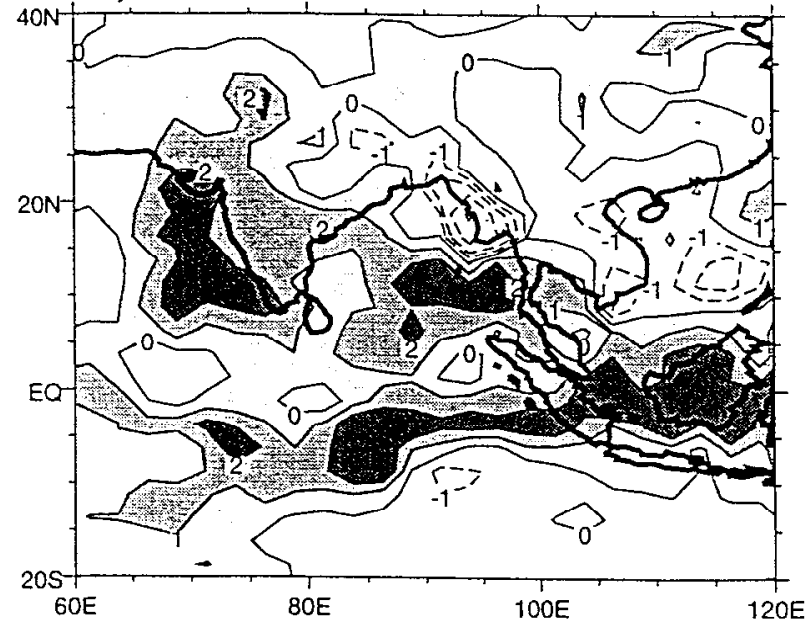

d) UKMO Ensemble mean

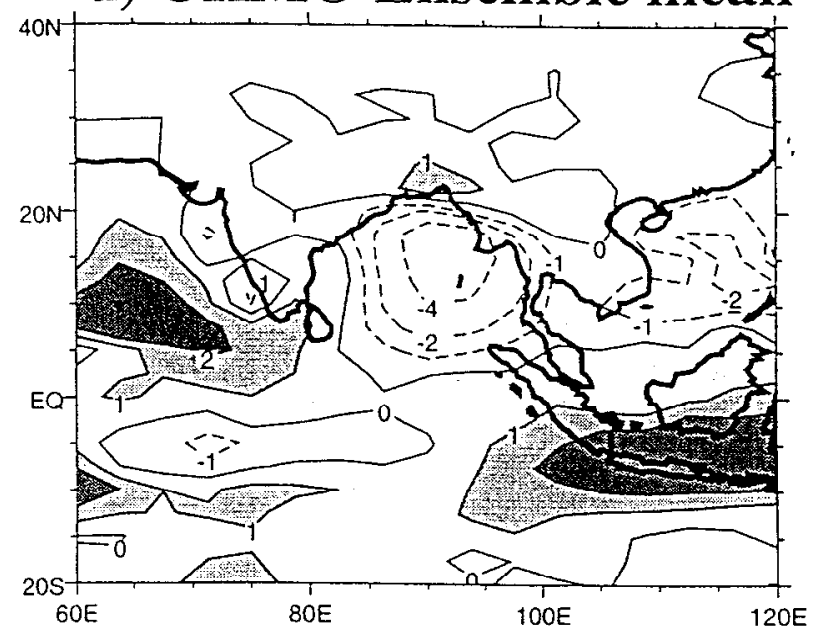

f) UKMO 31 May I.C.

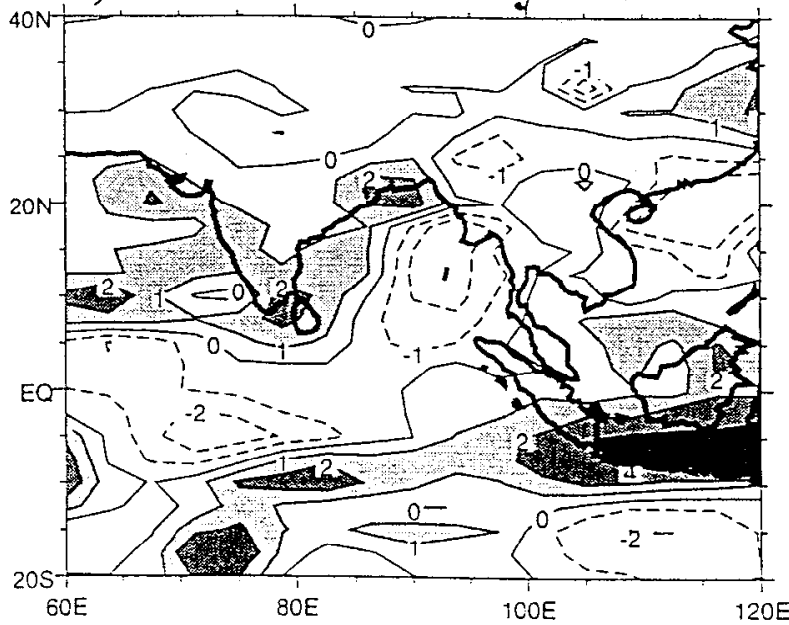

Figure 2: June-September seasonal mean anomalies for 1988 relative to the climatology for 1987 , 1988, and 1993. (a) NCEP/NCAR $850 \mathrm{hPa}$ wind $\left(\mathrm{m} \mathrm{s}^{-1}\right)$, (b) Xie and Arkin (1996) rainfall $\left(\mathrm{mm} \mathrm{day}^{-1}\right)$, (c) UKMO $850 \mathrm{hPa}$ wind from the full ensemble, (d) as (c) but for rainfall, (e) UKMO $850 \mathrm{hPa}$ wind from the 31 May 1988 initial condition integration, (f) as (e) but for rainfall. 